\title{
Assessment of environmental impact caused by the release of radionuclides in IIha Grande Bay after an accident at the nuclear power plant
}

\author{
Aguiar A. S. , Lamego Simoes Filho F. F., Lapa C. M. F., Soares A. D. \\ Institute of Nuclear Engineering, IEN/CNEN - LIMA, Rio de Janeiro, Brazil \\ Email address: \\ aguiargm@gmail.com (A. S. de Aguiar), flamego@ien.gov.br (F. F. L. S. Filho), lapa@ien.gov.br (C. M. F. Lapa), \\ asoares@cnen.gov.br (A. D. Soares)

\section{To cite this article:} \\ Aguiar A. S., Lamego Simoes Filho F. F., Lapa C. M. F., Soares A. D.. Assessment of Environmental Impact Caused by the Release of \\ Radionuclides in Ilha Grande Bay after an Accident at the Nuclear Power Plant. International Journal of Environmental Monitoring and \\ Analysis. Vol. 2, No. 6, 2014, pp. 340-346. doi: 10.11648/j.ijema.20140206.17
}

\begin{abstract}
This study aimed to evaluate the impact of a postulated accidental release of radionuclides from a nuclear power reactor into the aquatic resources, using an environmental modeling. To achieve that, computational models of hydrodynamics and transport were used to simulate the radionuclides dispersion caused by an accident in a PWR. This exercise was accomplished with the aid of a code system (SisBAHIA) developed at Rio de Janeiro Federal University (COPPE/UFRJ). The nuclear power plant Angra 3 is a reactor that uses pressurized light water as moderator and coolant in the core. Where $431 \mathrm{~m}^{3}$ of soda almost instantaneously was lost. This inventory contained $1.87 \times 10^{10} \mathrm{~Bq} / \mathrm{m}^{3}$ of tritium, $2.22 \times 10^{7} \mathrm{~Bq} / \mathrm{m}^{3}$ of cobalt, $3.48 \times 10^{8}$ $\mathrm{Bq} / \mathrm{m}^{3}$ of cesium and $3.44 \times 10^{10} \mathrm{~Bq} / \mathrm{m}^{3}$ of iodine and was released in liquid form near the Itaorna cove, Angra dos Reis - RJ. Applying the model in the proposed scenario [1-2], the simulated dilution of the specific activity of radionuclide spots, reached values much lower than report levels for seawater $\left(1,1 \times 10^{6} \mathrm{~Bq} / \mathrm{m}^{3}, 1,11 \times 10^{4} \mathrm{~Bq} / \mathrm{m}^{3}, 7,40 \times 10^{2} \mathrm{~Bq} / \mathrm{m}^{3}\right.$ and $\left.1,85 \times 10^{3} \mathrm{~Bq} / \mathrm{m}^{3}\right)$ after 22 hours, respectively for ${ }^{3} \mathrm{H},{ }^{60} \mathrm{Co},{ }^{131} \mathrm{I}$ and ${ }^{137} \mathrm{Cs}$.
\end{abstract}

Keywords: LOCA, Radionuclide Dispersion, Radiological Impact, PWR Reactor, SisBahia

\section{Introduction}

The mathematical models that represent hydrodynamics and contaminant transport in water bodies are generally based on conceptual laws or principles expressed by differential equations. Numerical or Numerical-Analytical models translate mathematical equations to computational language (e.g. finite differences, finite elements, finite volumes or probabilistic models) and have high predictive power and little loss of information. The uncertainty can be largely reduced with calibration process and model validation. For these reasons, the recommendation to move from box-model hydrological models (with high uncertainty level) to hydrodynamic process-oriented numerical modeling should be considered as an important issue for radionuclide transport.

The hydrodynamics of the most part of natural aquatic bodies is extremely complex due to the irregular geometric shape and also because of the diversity of features that produce the flow. The main forcing parameters are the winds, river discharges to the watersheds, tides and water density. To get forcing data is necessary to monitor in situ variations of water level, wind direction and speed, tide currents, temperature and salinity, because this parameters help to understand the hydrodynamic processes and establish the conceptual model. The models are equation systems capable to quantify the flow and represent a practical way to forecast the behavior of water bodies.

They are used to infer about known or hypothetical scenarios, allowing the better understanding of the system that are fundamental to decision makers, especially in accident situations. In case of accidental releases of liquid wastes from nuclear power plants, the previous knowledge about the advection and turbulent diffusion pathways in different scenarios are critical to provide the hydrodynamics basic information to simulate dispersion of radioactive pollutants [3].

In this work we have used the Database System for Environmental Hydrodynamics SisBAHIA ${ }^{\circledR}$ that is a computational model applied to hydrodynamic circulation and advection-diffusion contaminant transport. It is suitable 
for natural or man-made water bodies under different meteorological, fluvial, lacustrine or oceanographic scenarios and was developed by the Program on Coastal and Oceanographic Engineering of Federal University of Rio de Janeiro since 1987. It runs on FORTRAN programming language.

\section{Methodology and Modeling Approach}

In all cases pertinent to modeling the transport of water constituents and determining their fate during a period of about a month, the focus will be in the far field. That is, in regions sufficiently far from the water outlets, away from the active turbulent mixing zones typical of the jets that forms in the near field of the outlets. In these far regions, the plumes of constituents, including those of heated water, are passively transported by the prevailing currents. Thus, in a far field sense, the considered water constituents, including heat and particulate substances, can be treated as passive scalars.

The passive scalar approach allows the decoupling of the transport modeling from the hydrodynamic circulation modeling. In this respect, the implicit hypothesis is that the hydrodynamic circulation in the far field is independent of the concentration distribution of a given constituent.

The decoupling of the transport model from the hydrodynamic model allows the negligence of baroclinic forcing in the later. Therefore, in order to model the transport of constituents for a given scenario, the pertinent hydrodynamic circulation will be previously modeled. That is so, because velocity fields and large-scale turbulence parameters, which are necessary input data for the transport models, are computed by the hydrodynamic models.

The modeling approach is dependent on the features of the adopted modeling system that must comply with to the physics of the problem. The models for the simulations of hydrodynamic circulation and transport of contaminants to be used in this project pertain to a system called SisBAHIA®, as described below.

\subsection{Hydrodynamical Modeling Approach}

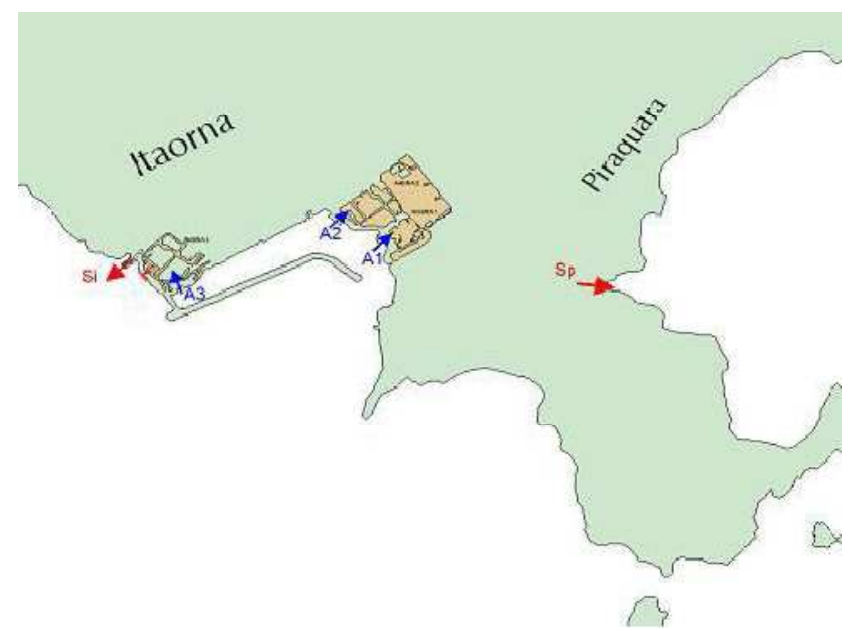

Figure 1. Nuclear Power Plants showing the water intake and discharge design in a possible scenario for Angra III.
The general modeling approach was to include the whole bay in the modeling domain, and use finite element discretiation techniques to model in proper detail the areas of interest around the Itaorna cove. The figure 1 illustrate these techniques respectively for the present situation, and for the situation foreseen the construction of Angra 3 [4].

The 3D spatial discretization is done via a vertical stack of sub-parametric finite element meshes using $\sigma$ coordinate transformation along the vertical dimension. That is, if one looks from the top, one sees the horizontal plane of the domain discretized by a single mesh of finite elements. However, in fact, there will be a stack of meshes, one for every $\sigma$ level. In this way, vertical discretization is done automatically once the user defines the number of desired $\sigma$ levels (usually between 10 and 50).

Elements in a mesh are sub-parametric, for that, the variables in each element are defined by quadratic Lagrangian polynomials whereas the element geometry is defined by linear Lagrangian polynomials. Elements in a mesh can be quadrilaterals and/or triangles. Quadrilaterals are preferred, because variables become bi-quadratic, and thus have a higher accuracy. In addition, the scheme allows very good representation of domains with complex geometries and bottom topography, as in the case of Ilha Grande Bay.

Temporal discretization is done through a 2 nd order implicit factored scheme for nonlinear terms and a Crank- Nicholson scheme for linear terms. Phase errors are minimized because all terms in the numerical scheme are centered at the same instant, $t=(n+1 / 2 \Delta t)$. Open boundaries elevations and current velocities can be prescribed in many different ways, including synthetic tides generated by given harmonic constants, and data measured or provided at discrete times. A different value, and/or phase shift, can be given for each node along any open boundary segment.

Land boundaries can prescribe either normal or imposed directional fluxes or velocities. Fluxes or velocities can be constant or variable in time, (a river discharge curve for instance). Leaky boundaries are allowed. Slip and no-slip boundaries are allowed, and the equivalent roughness along each boundary node can be prescribed. Surface and bottom boundary conditions for the 3D model, when zero velocity is the bottom boundary condition, and the wind stress is the free surface condition. The model accepts inputs of wind fields that can be variable in space and time. The amplitude of the equivalent bottom roughness can be specified for each bottom node for computing the bottom stresses, reflecting the type of material (rock, sand, mud, vegetation, etc.).

The computed friction coefficients of the bottom vary dynamically in time and space. A multi scale model is employed to model turbulence with horizontal sub grid scale turbulent stresses based on filtering techniques, also known as Large Eddy Simulation (LES) [5].

\subsection{Coolant Accidental Release from PWR Reactor}

The third unit of the Central Nuclear Almirante Álvaro Alberto (CNAAA) will have a PWR reactor of the same kind that is currently in operation in the unit 2 . For this reason we 
used the same information from Angra II [6].

The coolant is circulated at a flow rate of $18,800 \mathrm{~kg} / \mathrm{s}$ through four loops, each containing one stage high flux vertical centrifugal pump driven by constant speed electric motor (reactor coolant pump) and a generator of vapor exchanges heat with the water of the secondary system. The coolant enters the bottom of the core with temperature of approximately $291.3{ }^{\circ} \mathrm{C}$ and exits from the top at $326.1^{\circ} \mathrm{C}$, with the reactor at full power, at a constant pressure of $157 \mathrm{bar}$ through a pressurizer located in one of the reactor cooling circuit. The cooling system of the reactor is closed and separated from water and steam circuits of the secondary system, thus becoming as one of the barriers against the release of radioisotopes to the environment.

The water circulation, which makes up the third cycle, is separate from the primary and secondary cycle and used for condensing the exhaust steam of low pressure turbines. The water used in this cycle is taken from the sea in the Itaorna cove, near the plants $\left(40 \mathrm{~m}^{3} / \mathrm{s}\right.$ for Angra I, $77 \mathrm{~m}^{3} / \mathrm{s}$ for Angra II and equally for Angra III). Nowadays, these waters are entirely discharged in an outlet located at Piraquara cove (SPF) in the Ribeira Bay, accounting for a flow of $117 \mathrm{~m}^{3} / \mathrm{s}$, from the two operating units CNAAA.

Fig 1 shows the site of Angra III, still under construction, for which one alternative design would be release these waters in Itaorna. To avoid recirculation of thermal plume from Itaorna to the plant water intakes, the closure of the current outlet in the safety mole, next to Angra 3, was proposed.

This scenario represents the most conservative description to the dispersion of radionuclides from accident conditions, since the pollutant transport would be made in less restrictive conditions, i.e. more open circulation. The most critical design basis accidents are linked to the loss of primary coolant. The Loss of Coolant Accident - LOCA ranges from small leaks to large ruptures in the pipes of the reactor cooling system. The worst sequence is the guillotine break, LBLOCA of a system of pipes, resulting in the flow of refrigerant from both ends of the break.

In this study, the postulated accident is basically the total breakdown of the hot leg and the area considered for the rupture is $4418 \mathrm{~cm}^{2}$, which corresponds to $100 \%$ of the flow in pipes of the primary circuit. The thermo-hydraulic processes involved in the accident phenomenology such as the vaporization of the leg due to blow down of the primary circuit and consequently the emergence of the two-phase flow in this circuit. This should lead to a reduction of the fluid level and the discovery of the core, until the pressure of the primary circuit is the same as of the containment.

At the time of the accident, that the inventory of the primary flow rate, i.e, $431 \mathrm{~m}^{3}$, could not be retained in the containment of Angra III. It would flow through the pluvial water circuit being released into the sewage discharge channel in Itaorna cove during one hour, which means a flow of $0.12 \mathrm{~m}^{3} / \mathrm{s}(431$ $\left.\mathrm{m}^{3} / 3600 \mathrm{~s}\right)$.

\subsection{Transport Modeling Approach}

The Eulerian transport model in SisBAHIA® [7] solves the following conservation equation:

$$
\begin{gathered}
\frac{\partial C}{\partial t}+\mu_{i} \frac{\partial C}{\partial x_{i}}=\frac{1}{h} \frac{\partial}{\partial x_{i}}\left(h D_{i j} \frac{\partial C}{\partial x_{j}}\right)-\left(k_{d}+k_{s}\right) C+q_{s}\left(C_{s}-\right. \\
C) ; i, j=1 ; 2
\end{gathered}
$$

Where:

- $\mathrm{C}(\mathrm{x}, \mathrm{y}, \mathrm{t})=$ is the concentration averaged over height on the water column or thickness of a surface layer $\mathrm{h}(\mathrm{x}, \mathrm{y}, \mathrm{t})$;

- $\mathrm{u}_{\mathrm{i}}(\mathrm{x}, \mathrm{y}, \mathrm{t})=$ is the velocity component in the $\mathrm{xi}$ direction averaged over $\mathrm{h}(\mathrm{x}, \mathrm{y}, \mathrm{t})$;

- $\mathrm{D}_{\mathrm{ij}}(\mathrm{x}, \mathrm{y}, \mathrm{t})=$ is the turbulent diffusion and dispersion tensor averaged over $\mathrm{h}(\mathrm{x}, \mathrm{y}, \mathrm{t})$;

- $\mathrm{k}_{\mathrm{d}}=$ is the time rate of mass consumption $(\mathrm{kd}>0)$ or production $(\mathrm{kd}<0)$;

- $\mathrm{k}_{\mathrm{s}}(\mathrm{x}, \mathrm{y}, \mathrm{t})=$ is the time rate of removal of mass due to settling processes;

- $\mathrm{q}_{\mathrm{s}}(\mathrm{x}, \mathrm{y}, \mathrm{t})=$ is the discharge per unit horizontal area at a source region;

- $\mathrm{C}_{\mathrm{s}}(\mathrm{x}, \mathrm{y}, \mathrm{t})=$ is the concentration at the source region.

For the simulations of reference contaminants presented here the variable $\mathrm{h}(\mathrm{x}, \mathrm{y}, \mathrm{t})$ is the whole water column. The time rate of removal of mass due to settling process is computed as:

$k_{s}=\frac{-\ln (0.1)}{h / v_{s}}$ if $\left(\frac{\tau_{0}}{\tau_{0 c}} \leq 1-a\right)$ or $\left(\frac{\tau_{0}}{\tau_{0 c}}-1+a<2 a \times R[0 ; 1]\right)$
$k_{s}=0.0$ if $\left(\frac{\tau_{0}}{\tau_{0 c}} \geq 1+a\right)$ or $\left(\frac{\tau_{0}}{\tau_{0 c}}-1+a>2 a \times R[0 ; 1]\right)$

Where $V_{S}$ is a constant characteristic settling velocity given by the user, $\tau_{0}(\mathrm{x}, \mathrm{y}, \mathrm{t})$ is the stress exerted by the flow at the bottom of the layer with thickness $h, \tau_{0 c}$ is the critical bottom stress necessary to mobilize the particles settling with velocity $\mathrm{V}_{\mathrm{S}}$. The parameter $\mathrm{a}$ is a tolerance parameter between 0 and 0.5 , and $R[0,1]$ is a random number with values between 0 and 1 . If the user prescribes values for $V_{S}$, $\tau_{0 \mathrm{c}}$, and $\mathrm{a}$, the model computes $\mathrm{K}_{\mathrm{s}}$, which varies in time and space.

If the user prescribes values for $\mathrm{V}_{\mathrm{S}}, \tau_{0 \mathrm{c}}$, and $\mathrm{a}$, the model computes $\mathrm{K}_{\mathrm{s}}$, which varies in time and space. When $\tau_{0} / \tau_{0 \mathrm{c}}<$ $(1-\mathrm{a})$ turbulence is weak and settling occurs $\left(\mathrm{K}_{\mathrm{s}}>0\right)$. When $\tau_{0} / \tau_{0 \mathrm{c}}>(1+\mathrm{a})$ turbulence is too strong and there is no settling, since $\mathrm{K}_{\mathrm{s}}=0$. When $(1-\mathrm{a})<\tau_{0} / \tau_{0 \mathrm{c}}<(1+\mathrm{a})$ the settling processes becomes probabilistic. Note that if $\tau_{0} / \tau_{0 \mathrm{c}}=$ 1 there is a $50 \%$ chance of occurring settling. As $\tau_{0} / \tau_{0 \mathrm{c}} \rightarrow$ (1 - a) the chances of settling increase, and as $\tau_{0} / \tau_{0 c} \rightarrow(1+a)$ the chances decrease.

Since $\mathrm{K}_{\mathrm{s}}$ vary in space and time it is not a rate constant as $\mathrm{k}_{\mathrm{d}}$, which is indeed a constant, is a variable local rate of removal of suspended mass in the water column due to settling. Some models, simply use $K_{s}=V_{S} / h$, which is the inverse of the maximum settling time $\left(\mathrm{T}_{\mathrm{s}}\right)$ for a particle with a settling velocity $V_{S}$ in a water column of height $h$. $T_{s}$ can be considered a characteristic settling time. From a simple geometric reasoning, after a time $\mathrm{T}_{\mathrm{s}}$ all particles should have settled. However, solving the equation for a still water 
situation one finds that after a time equal to $\mathrm{T}_{\mathrm{s}}$ about $37 \%$ of the particles would remain in suspension. In addition, this simpler formulation allows settling even if, in reality, the flow is too turbulent for the occurrence of deposition in the bottom.

The formulation in eq. (2) is more realistic that the simplified formulation adopted in other models for two reasons [8]:

- Mass is only removed from the water column, in a given position, when the flow is such that effective deposition in the bottom might occur. That is, when, and so, the flow is quiescent enough for deposition to occur. The use of a tolerance value "a" is to account for the fact that usual criteria for defining critical bottom shear is not exact. The Shields curve for instance is just an adjusted curve in the middle of a cloud of experimental data.

- In a quiescent flow situation, $90 \%$ of the suspended particles will be deposited after a time equal to $T_{\mathrm{s}}$. Theoretically $100 \%$ should have deposited, thus the model is still conservative, but not unrealistic.

The terrestrial boundary conditions imposed in present and future scenarios considered uptake and discharge in Itaorna cove, only discharge for Piraquara cove and included recirculation effects. At all other land boundary points the prescribed condition was of zero contaminant flux in the normal direction to the boundary.

For open boundary points presenting inflow situations, the following conditions are used:

$$
\begin{gathered}
T=T_{0}+\frac{T^{*}-T_{0}}{2}\left[1-\cos \left(\frac{\pi\left(t-t_{0}\right)}{t}\right)\right] \text { when }\left(t-t_{0}\right) \leq \tau \\
T=T^{*} \text { when }\left(t-t_{0}\right)>\tau
\end{gathered}
$$

where $T^{*}(t)$ are prescribed values; $T_{0}$ is the value of the concentration calculated at the boundary point in the instant $\mathrm{t}_{\mathrm{o}}$, which is the instant immediately before the outflow changed to inflow situation. $\tau$ is a prescribed transition period, which depends on the modeler experience or available data. Usual values for $\tau$ are in the range of half an hour to two hours.

This kind of condition is particularly useful in modeling estuarine boundary conditions. In outflow situations, the model simply computes the transport equation with no diffusive terms along the open boundary points.

\section{Hydrodynamic Model Remarks}

The main aspects of hydrodynamic modeling are presented for a future scenario, involving discharges in Piraquara de Fora cove for Angra 1, 2 and discharges in Itaorna for Angra 3.

The figure 2, present typical current patterns respectively for flooding tides and ebbing tides. For this case, it is irrelevant to compare situations in spring and neap tides because the visual aspect is practically the same. That is so, for the following reasons:

- The circulation patterns in Itaorna cove are dominated by the inflow discharges of Angra 1, 2 and 3 at the entrance of the breakwater, and the outflow discharge of Angra 3. Current patterns in Piraquara cove are mainly affected by the outflow discharge of Angra 1 and 2.

- Tidal components in the prevailing currents are very small, with magnitudes often smaller than $0.05 \mathrm{~m} / \mathrm{s}$. The changes in the magnitudes of flooding and ebbing tidal components within Itaorna cove and Piraquara cove, from spring to neap tides are subtle, in comparison to the prevailing circulation caused by the power plant discharges.
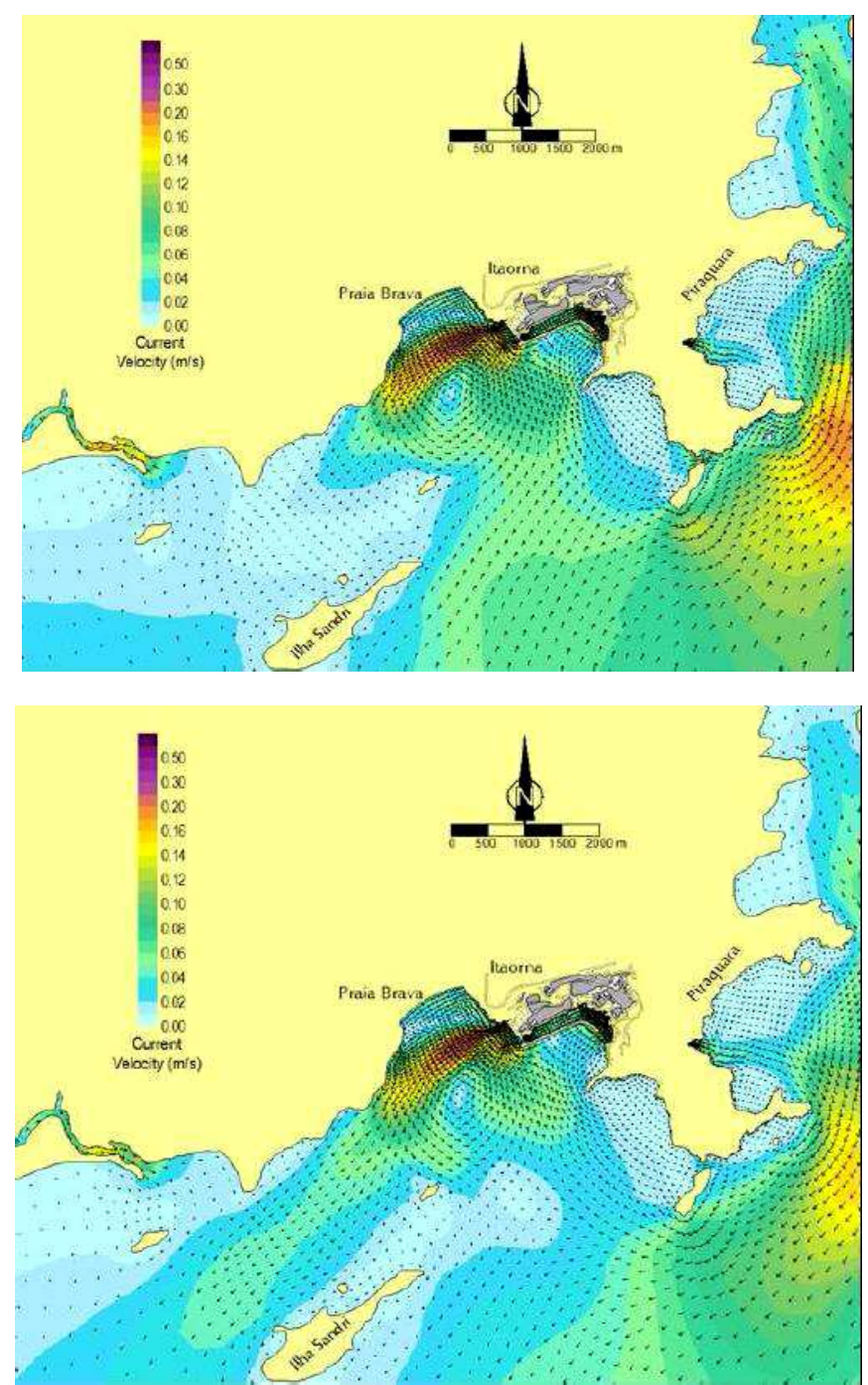

Figure 2. Typical current pattern in Future Scenario for flooding (above) and ebbing (below) tides.

By examining figure 2, one sees that the recirculating cells formed by the effluent jet from Angra 3 are quasi steady, and quite insensitive to tidal conditions. The aspect of the recirculating cells remains practically the same during flood and ebb tides. It is interesting to note that during flooding tides the jet form Angra 3 opposes the natural flow in the channel to the North of Sandri Island, producing a stagnant zone in that region.

Conversely, during ebbing tides, the jet from Angra 3 enhances the natural flow. A similar effect also occurs in 
Piraquara cove, when natural flooding currents are opposed by the effluent jet from Angra 1 and 2, while in ebbing tides the jet enhances the flow.

\section{Radionuclide Transport Simulation}

All radioactive elements produced in a nuclear power plant have their origin in the reactor core or in the vicinity. The two major processes responsible for their presence are nuclear fission and neutron activation. The fission products are largely responsible for radioactivity, but they are produced inside the fuel, so they have to cross the ceramic pellets of fuel moving through diffusion through the free space between them and the wall of the fuel rod and reach the water in the primary. Activation by neutrons can occur in or out of fuel, simply by the presence of a neutron flux.

From the inventory of radioactivity generated by the reactor coolant of PWR Angra III, we chose to simulate the radionuclides representing both fission products and corrosion, which showed high concentrations and high rates of assimilation and thus more radiation risk.

The radionuclides chosen to fit these criteria were the ${ }^{137} \mathrm{Cs}$, ${ }^{131} \mathrm{I}$ and ${ }^{60} \mathrm{Co}$, respectively. In addition, it was chosen Tritium $\left({ }^{3} \mathrm{H}\right)$ due to its conservative behavior and particular characteristics in the transfer within the aquatic food chain. The tritium behavior was considered conservative once it forms the water molecule like its isotope hydrogen and remains in solution.
The source term characteristics, according to the mentioned radionuclides, as initial activity concentration, waste load, reporting levels of the coolant inventory, as dispersion results obtained by the model are showed in table 1 .

The radionuclides released in the discharge channel were diluted 640 times $\left(0.12 \mathrm{~m}^{3} / \mathrm{s} \div 77 \mathrm{~m}^{3} / \mathrm{s}\right)$ before reach Itaorna. The pollutant load was distributed in three nodes of the bay mesh at the outlet of discharge channel.

The initial concentration of radionuclides was held absent in the remaining of the domain. The boundary conditions for land (closed) and sea (open) were defined as zero for all nodes, except those three mentioned above. The time step was fixed in $100 \mathrm{~s}$, which yields suitable courant number simulate the dispersion after the accident during up to 180 days.

The results are present for instant $t$ corresponding to the half-live of flooding and ebbing tides (22 and 54 hours), when the currents are faster. After this period the concentration values are pretty lower, diluted up to ten thousand times. The results are compared with values prescribed lower limit of detection and reporting levels for radioactivity concentration in water.

The report specification is provided to ensure that the concentration of radioactive materials released in liquid waste effluents from the site will be less than the value applicable to the assessment and control of dose to the public. This limit is equivalent to the radionuclide concentrations which, if inhaled or ingested continuously over the course of a year, would produce a total effective dose equivalent of $0.5 \mathrm{mSv}$ [9].

\subsection{Source Term Characterization}

Table 1. The values of waste and initial concentration, load and report levels and model results.

\begin{tabular}{|c|c|c|c|c|}
\hline $\begin{array}{l}\text { Discharge }-0.12 \mathrm{~m}^{3} / \mathrm{s}-\text { coolant } \\
\text { inventory concentration }\left(\mathrm{Bq} / \mathrm{m}^{3}\right)\end{array}$ & $\begin{array}{l}\text { Initial concentrarion } \\
\left(\mathbf{B q} / \mathbf{m}^{3}\right)\end{array}$ & Pollutant Load (Bq/s) & $\begin{array}{l}\text { Report level seawater } \\
\left(\mathbf{B q} / \mathbf{m}^{3}\right)\end{array}$ & $\begin{array}{l}\text { Model results max-min } \\
\left(\mathrm{Bq} / \mathrm{m}^{3}\right)\end{array}$ \\
\hline${ }^{3} \mathrm{H}-1.87 \times 10^{10}$ & $2.90 \times 10^{7}$ & $3.50 \times 10^{6}$ & $1.11 \times 10^{6}$ & $5.0 \mathrm{E}+03-5.0 \mathrm{E}-02$ \\
\hline${ }^{60} \mathrm{Co}-2.20 \times 10^{7}$ & $3.50 \times 10^{4}$ & $4.20 \times 10^{3}$ & $1.11 \times 10^{4}$ & $2.5 \mathrm{E}-01-2.5 \mathrm{E}-04$ \\
\hline${ }^{131} \mathrm{I}-3.40 \times 10^{10}$ & $5.30 \times 10^{7}$ & $6.40 \times 10^{6}$ & $7.40 \times 10^{2}$ & $1.0 \mathrm{E}+03-1.0 \mathrm{E}-01$ \\
\hline${ }^{137} \mathrm{Cs}-3.50 \times 10^{8}$ & $5.05 \times 10^{5}$ & $6.00 \times 10^{4}$ & $1.85 \times 10^{3}$ & $1.5 \mathrm{E}+01-1.5 \mathrm{E}-03$ \\
\hline
\end{tabular}

\subsection{Modeling Results}

The figures 3, 4, 5 and 6 show the radionuclide plumes in Ilha Grande Bay after 22 and 54 hours of the postulate accident, respectively for ${ }^{3} \mathrm{H},{ }^{137} \mathrm{Cs},{ }^{60} \mathrm{Co}$ and ${ }^{131} \mathrm{I}$. 

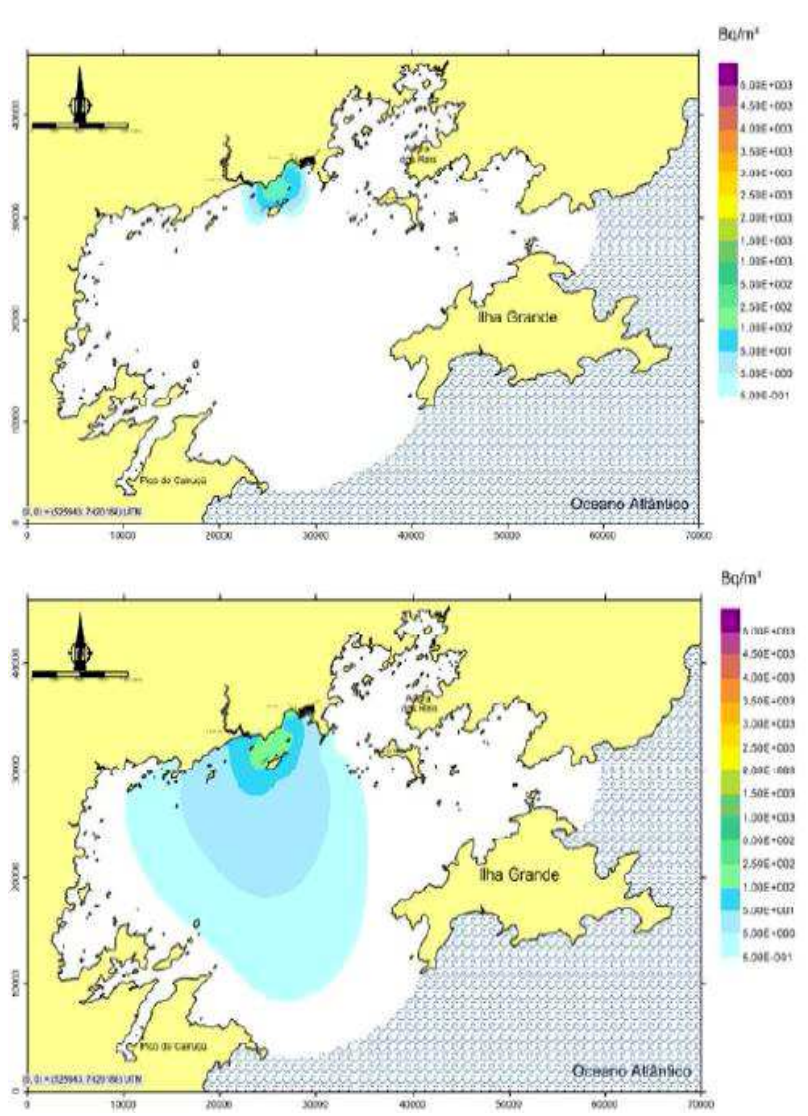

Figure 3. Results of tritium dispersion in Ilha Grande Bay obtained by transport modeling after 22 hours (above) and 54 hours (below) the postulate accident.
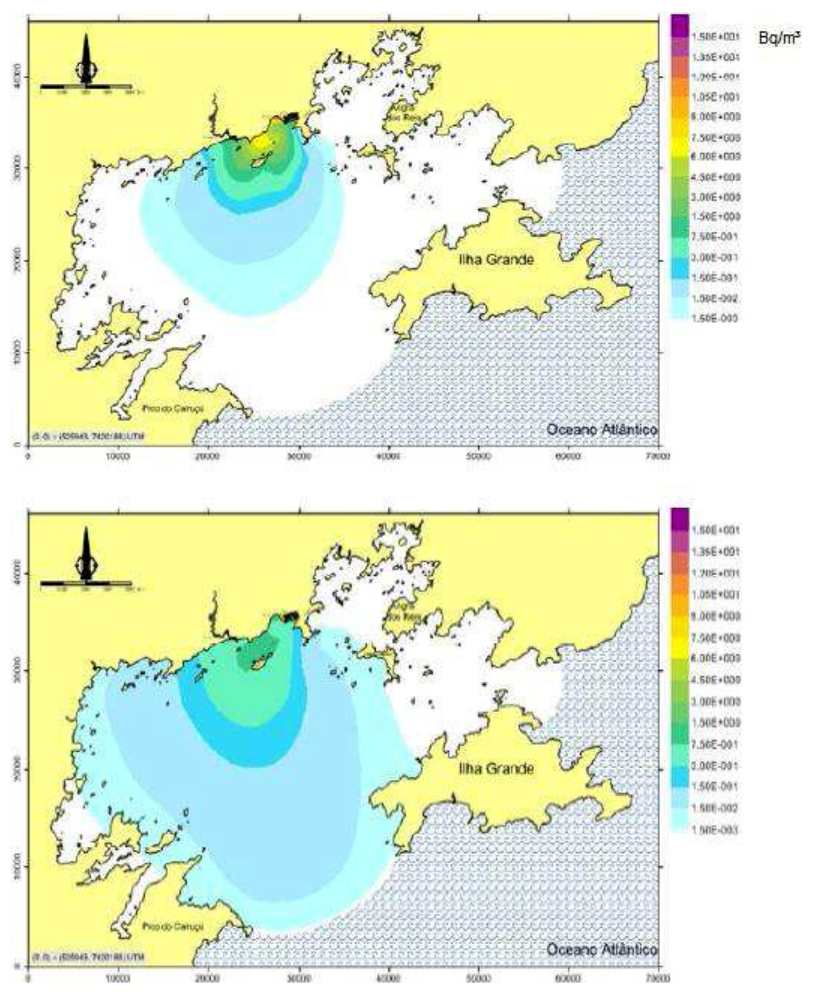

Figure 4. Results of cesium-137 dispersion in Ilha Grande Bay obtained by transport modeling after 22 hours (above) and 54 hours (below) the postulate accident.
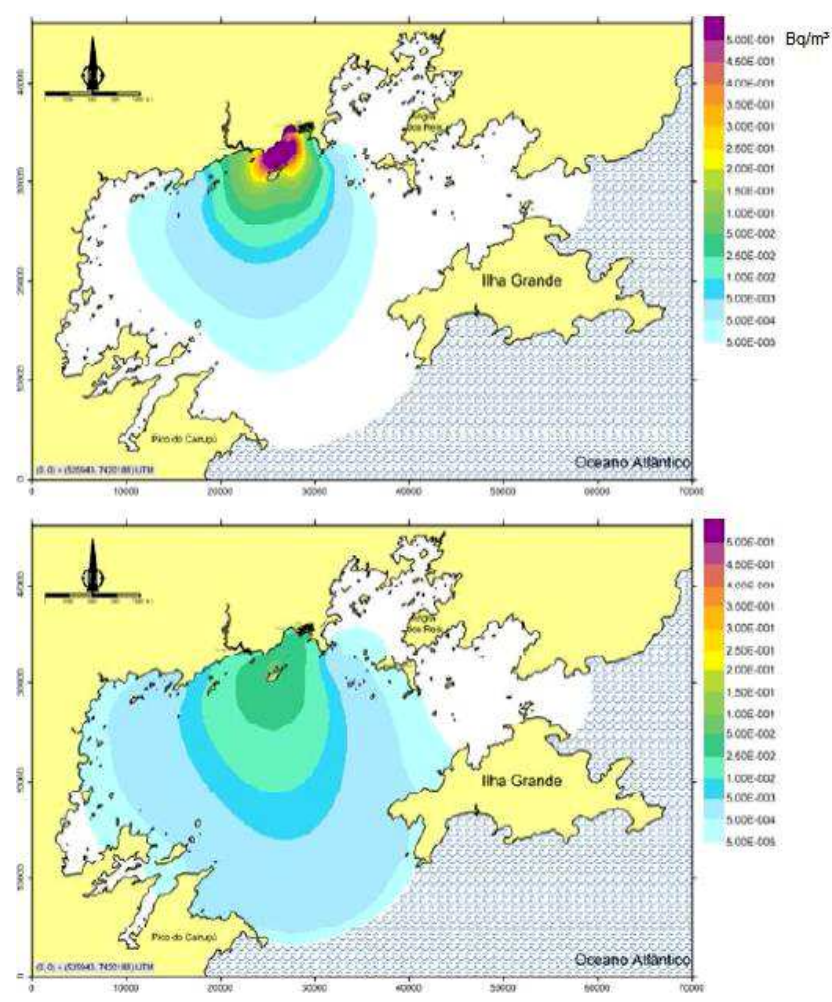

Figure 5. Results of cobalt-60 dispersion in Ilha Grande Bay obtained by transport modeling after 22 hours (above) and 54 hours (below) the postulate accident.
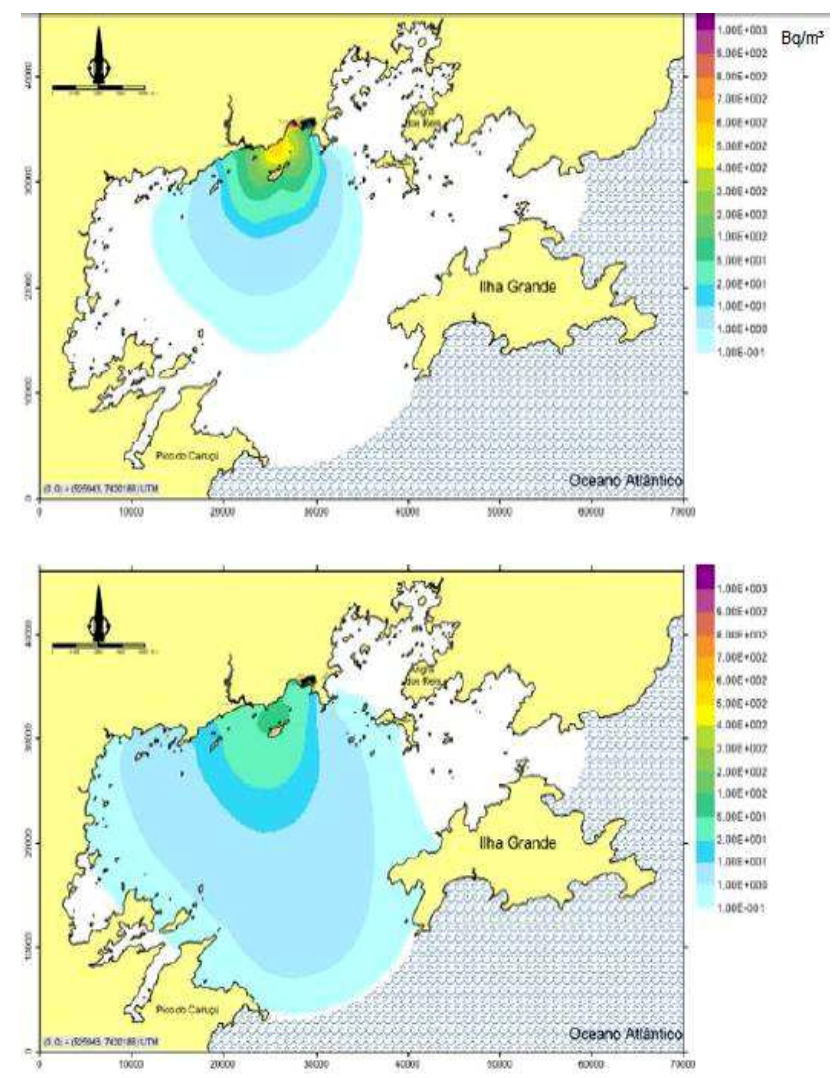

Figure 6. Results of iodine-137 dispersion in Ilha Grande Bay obtained by transport modeling after 22 hours (above) and 54 hours (below) the postulate accident. 
The values are in general pretty lower than the reference values showed at table 1 . In general, the values for each radionuclide are not detected by the analytic methods applied in monitoring programs, whose minimum activities for radionuclide determination are higher than model results.

Influence zones were defined in the plant licensing for preparedness to emergency situations. The area of direct influence is limited to a radius of $5 \mathrm{~km}$ around the project, according to the dispersion of waste that can directly impact the biota, through exposure or contamination by radiation.

The area of indirect influence is set to a radius of $10 \mathrm{~km}$, corresponding to possible dispersion of radioactive pollutants that could occur in weather conditions and unusual mare.

Comparing the results of the numerical model up to a distance of approximately $2.5 \mathrm{~km}$ from the source, where the largest activity concentrations are observed after 22 hours for ${ }^{3} \mathrm{H}-10,{ }^{60} \mathrm{Co}-2,5 \times 10^{-1},{ }^{131} \mathrm{I}-1.5 \times 10^{3}$ and ${ }^{137} \mathrm{Cs}-13.5 \mathrm{~Bq} / \mathrm{m}^{3}$, with report levels in seawater for the ${ }^{3} \mathrm{H},{ }^{60} \mathrm{Co},{ }^{131} \mathrm{I}$ and ${ }^{137} \mathrm{Cs}$, respectively $1.11 \times 10^{6}, 1.11 \times 10^{4}, 7.4 \times 10^{2}$ and $1.85 \times 10^{3}$ $\mathrm{Bq} / \mathrm{m}^{3}$ [9], we can conclude that only ${ }^{131} \mathrm{I}$ presented values higher than the reference, but only for this very restricted area and during a very short time lag.

This is in agreement with the fact that Iodine is usually the first radionuclide widespread in the environment after radiological accidents.

For the area of indirect influence, the concentration gradients, after $5 \mathrm{~km}$, at the time of 54hours, usually have values below the minimum detection level, whose values are for the ${ }^{3} \mathrm{H},{ }^{60} \mathrm{Co},{ }^{131} \mathrm{I}$ and ${ }^{137} \mathrm{Cs}$, respectively $5.2 \times 10^{4}, 3.0 \times 10^{2}$, $5.0 \times 10^{1}$ and $2.5 \times 10^{2} \mathrm{~Bq} / \mathrm{m}^{3}$ [9]. The exception for Iodine is noticed again.

\section{Conclusion}

This study evaluated an aquatic impact scenario of a PWR reactor, which corresponds to the most serious situation that may occur in terms of accident involving the exclusive release of effluents on the aquatic environment.

In this context, we chose to simulate the accident from Angra 3 with release of the source term directly in Itaorna, as this would be the worst possible condition in terms of dispersion of radionuclides, once Itaorna is a wide cove and with faster circulation than the current point of discharge (Piraquara de Fora).

It is important to note that in the initial moment, in the first 22 hours, the radionuclides concentrations are bigger than the detection limits values, but they do not exceed the sea water limits. However the local isolation is already provided in the emergency plans of the installation, once the biggest values are in the direct influence area ( $5 \mathrm{~km}$ from NPP).

About the population exposition to the simulated radionuclides presents in the effluents of CNAAA, the activity concentrations obtained from the model suggests that there are not significant radiological impacts after 22 hours according the IAEA recommended limits of detection, sea water limits references and the minimum limits of activity detected by the Ambiental Monitoration Laboratory of Angra 2.

Thus we can conclude that there is no impediment to the release, the simulated radionuclides, in Itaorna.

\section{Acknowledgements}

We would like to thank the Eletrobrás Eletronuclear to have yielded information that support the model simulations presented in this work. Thanks are also due to the Nuclear Science and Technology Graduate Program of IEN that have granted scholarships to students who are authors of the work. Financial support is partially provided by CAPES (PNPD).

\section{References}

[1] F. F. Lamego Simões Filho, C. M. F. Lapa, A. S.Aguiar, A. D. Soares. Radionuclide dispersion and hydrodynamics of Ilha Grande Bay (Angra dos Reis, RJ) simulated from hypothetical accidental releases of liquid wastes. Instituto de Engenharia Nuclear: Progress Report Coordination of Management and Infrastructure, 2011-2012. Rio de janeiro, Brazil, pag 102, 2013.

[2] F. F. Lamego Simões Filho, A. S. Aguiar, A. D.Soares, C. M. F. Lapa. Modelling the transport of radionuclides released in the Ilha Grande bay (Brazil) after a LBLOCA in the primary system of a PWR. Instituto de Engenharia Nuclear: Progress Report Coordination of Management and Infrastructure, 2011-2012. Rio de janeiro, Brazil, pag 103, 2013.

[3] C-An Huh, et al. " Marine environmental radioactivity near Nuclear Power Plants in Northern Taiwan", Journal of Marine Science and Technology, Vol. 12, No. 5, pp. 418-423, (2004).

[4] COPPETEC. Environmental aspects concerning Angra 3. Final Report. PENO-4841. (2004)

[5] D. R. F. Halerman, Water Quality Control. Massachusetts Institute of Technology (1987).

[6] FSAR, Final Safety Analysis Report. Central Nuclear Almirante Álvaro Alberto - Unidade 2. Rev. 28 . Eletronuclear - Eletrobras S.A. (2010).

[7] P. C. C Rosman,. "Referência Técnica do SisBaHiA". http://www.sisbahia.coppe.ufrj.br/SisBAHIA_RefTec_V8.pdf (2009).

[8] P.C.C. Rosman, Modeling Shallow Water Bodies via Filtering Techniques. Ph.D. Thesis, Dept. of Civil Engineering, Massachusetts Institute of Technology (1987).

[9] NRC, National Regulatory Commission. "10 CFR Part Appendix A to Part 50-General Design Criteria for Nuclear Power Plants." http://www.nrc.gov/reading-rm/doccollections/ cfr/part050/part050-appa.html (2010). 